\title{
Stability and load-bearing capacity assessment of a deformed multi-span masonry bridge using the PRD method
}

\section{Antonino lannuzzo*, Tom Van Mele and Philippe Block}

\author{
Block Research Group (BRG), \\ Institute of Technology in Architecture (ITA), \\ Eidgenössische Technische Hochschule Zürich (ETH - Zurich), \\ Stefano-Franscini-Platz 1, HIB E, \\ CH-8093 Zurich, Switzerland \\ Email: iannuzzo@arch.ethz.ch \\ Email: vanmele@arch.ethz.ch \\ Email: block@arch.ethz.ch \\ *Corresponding author
}

\begin{abstract}
Most of the computational approaches based on Heyman's theory rely on the safe theorem and can only tackle kinematical problems (KPs) with non-homogeneous boundary displacements for simple geometries. So far, no computational tools have been developed to directly address the KP for generic 2D structures taking into account different mechanical scenarios and foundation settlements simultaneously. With this aim, compas_prd, a new computational Python-based tool has been developed. It is based on the piecewise rigid displacement (PRD) method, which couples the KP with the equilibrium problem (EP), allowing the search for a mechanism and its corresponding internal stress state even in large displacements. Both KP and EP are framed as linear programming problems, allowing fast computational solving. Looking at an approximate cross-section of a multi-span masonry bridge, different mechanical scenarios are addressed to illustrate the abilities of compas_prd, also taking into account an initial deformed configuration.
\end{abstract}

Keywords: masonry; historical structures; PRD method; limit analysis; settlements; large displacements; load-bearing capacity; seismic assessment.

Reference to this paper should be made as follows: Iannuzzo, A., Van Mele, T. and Block, P. (2021) 'Stability and load-bearing capacity assessment of a deformed multi-span masonry bridge using the PRD method', Int. J. Masonry Research and Innovation, Vol. 6, No. 4, pp.422-445.

Biographical notes: Antonino Iannuzzo is a post-doctoral researcher at the ETH Zurich, where he joined the Block Research Group (BRG) in 2018. He holds his $\mathrm{PhD}$ in 2017 with a dissertation entitled 'A new rigid block model for masonry structures' in which an energy-based method together with two numerical approaches were proposed to assess historic masonry structures, particularly in the case of foundation displacements. The energy criterion was formulated extending the total potential energy to no-tension materials. The two numerical approaches provide two opposite strategies to discretise the corresponding mathematical problem leading to smeared and concentrated cracks. His research currently focuses on the theoretical and computational models for the static, kinematic, and dynamic analysis of masonry structures. 
Tom Van Mele studied Architecture and Structural Engineering at the Vrije Universiteit Brussel in Brussels, Belgium, where he received his PhD in 2008 for a dissertation on the design and analysis of retractable membrane roofs. In 2010, he joined the Block Research Group, where his technical and computational developments have formed the backbone of the day-to-day research and of multiple flagship projects, including the Droneport and the Armadillo Vault, both presented at the 2016 Architecture Biennale in Venice, and the NEST HiLo roof prototype completed in the Robotc Fabrication Lab in 2017. He is currently the Co-Director and Head of research of the BRG, and a lead developer of COMPAS, an open-source computational framework for research and collaboration in architecture and structures.

Philippe Block is a Professor at the Institute of Technology in Architecture at ETH Zurich, where he co-directs the Block Research Group (BRG) together with Dr. Tom Van Mele. He is the Director of the Swiss National Centre of Competence in Research (NCCR) in Digital Fabrication, and founding partner of Ochsendorf DeJong and Block (ODB Engineering). He studied Architecture and Structural Engineering at the VUB, Belgium and MIT, USA, where he earned his $\mathrm{PhD}$ in 2009. His research focuses BRG on computational form finding, optimisation and construction of curved surface structures, specialising in unreinforced masonry vaults and concrete shells. Within the NCCR, BRG researchers develop innovative structurally informed bespoke prefabrication strategies and novel construction paradigms employing digital fabrication. With the BRG and ODB Engineering, he applies his research into practice on the structural assessment of historic monuments in unreinforced masonry and the design and engineering of novel shell structures.

\section{Introduction}

The assessment of masonry structures is a complex mechanical problem, mainly because of their negligible tensile strength (Heyman, 2019). Indeed, masonry constructions are typical structures characterised by a double unilateral constraint. These unilateral constraints allow them to accommodate small changes in the external environment reaching a new stable configuration (Heyman, 1966) where a rigid macro-block partition of the structural domain can be seen. This partition is defined by fractures, which are the peculiar manifestation of their intrinsic unilateral behaviour (Ochsendorf, 2002; Huerta, 2006a; Como, 2013; Angelillo et al., 2018). For this reason, standard tools adopted in practice and conceived for other materials cannot be applied (Block et al., 2006; Shin et al., 2016), mainly for their inability in catching zero-energy modes (e.g., crack pattern or mechanisms which reflects into ill-conditioned matrices).

One of the widely accepted approaches to face their assessment is to use limit analysis theory à la Heyman (Huerta, 2006b; Roca et al., 2007; Como, 2013). The Heyman model can be framed into the continuum mechanics using the so-called normal, rigid, no-tension (NRNT) material. It can be proved that its constitutive relations are equivalent to the classic normality and dual-normality relations adopted in Limit Analysis. In this sense, the boundary value problem (BVP) solution for an NRNT material intrinsically satisfies the classic limit analysis requirements (Angelillo, 2014). Moreover, for NRNT materials, a BVP solution can be found solving two opposite problems: an equilibrium problem (EP) and a kinematical problem (KP) (Angelillo et al., 
2018). Solving the EP means finding an admissible internal stress state in equilibrium with the external loads, compatible with prescribed boundary conditions and fulfilling the NRNT material requirements.

An efficient, robust and direct approach to the solution of EP is represented by the safe theorem of limit analysis, representing a standard lower bound approach to the BVP solution (Fraternali et al., 2002; Block and Ochsendorf, 2007; Block, 2009; Fraternali, 2010; Fraddosio et al., 2020; Bruggi, 2020; Angelillo et al. 2021). For advanced applications, the reader is referred to Marmo and Rosati (2017), Marmo et al. (2018), Monaco et al. (2019), Barsi et al. (2019), Aita et al. (2019), Brandonisio et al. (2020), Gesualdo et al. (2020) and Olivieri et al. (2021). The safe theorem's use requires only equilibrium considerations, and the stability is guaranteed when at least one thrust line, thrust network or purely compressed membrane lying entirely within the structural domain can be found (Heyman, 1966; Huerta, 2006b). Even though it was not rigorously framed, the safe theorem's use can be traced back to the 18th century. Consequently, an initial rigorous framing of the thrust line theory can be dated back to the early of the 19th century. Specifically, it is attributed to Gerstner in German literature, to Méry in French literature and Moseley in English one. For more info, the reader is referred to Rondeaux et al. (2018) and Kurrer (2018). Méry and Moseley were the first who correlate the thrust lines with possible collapse mechanisms. Nowadays thrust line analysis still represents an efficient methodology to assess the local stability of complex three-dimensional structures (Paris et al., 2020) or the global stability through the slicing technique (Fuentes, 2019; Cennamo et al., 2018b). Only in recent periods, computational tools to fully explore lower-bound solutions have been successfully proposed (Block, 2009; Block and Lachauer, 2014a, 2014b; De Chiara et al., 2019).

Solving the BVP KP means finding a displacement field that simultaneously satisfies constitutive relations, equilibrium requirements and, more importantly, non-homogeneous boundary conditions (Iannuzzo et al., 2018). Standard upper bound approaches based on the kinematic theorem of limit analysis can efficiently be used to assess the ultimate state of masonry structures, but they cannot take into account nonhomogeneous boundary displacements (Tralli et al., 2020). In this sense, they cannot be used to solve the kinematic problem in the presence of foundation displacements. Thus, no one computational tool suitable to solve the KP in presence of foundation settlements and for generic masonry 2D structures has been developed so far.

Moreover, despite great advances in the field and numerous efforts put by scientists into the development of computational tools especially also for the KP of generic masonry structures subjected to different scenarios of damage, the $2 \mathrm{D}$ problem remains unclear/has yet to be fully determined. Particularly, approaches and related computational tools especially for 2D masonry structures can properly reproduce only simplified geometrical forms (e.g., arched or trivial regular structures) for which either the qualitative mechanism is known or a specific selection of a number of mechanisms is made in advance. For an extensive discussion, the reader is also referred to Iannuzzo et al. (2021b).

The NRNT material employed to model masonry structures provides a consistent mathematical framework to the use of the total potential energy as the energy criterion to efficiently and consistently solve the KP, particularly in the presence of foundation displacements. Moreover, as proved in Angelillo et al. (2018), the dual-energy criterion, based on the minimisation of the total complementary energy, provides a robust approach 
to solve the EP and, in this sense, to couple mechanisms and internal stress states (Iannuzzo et al., 2020).

With this aim, a new Python-based computational tool, framed within COMPAS masonry (Iannuzzo et al., 2021a), is being developed: compas_prd. Is based on the piecewise rigid displacement (PRD) method (Iannuzzo, 2017) and solves both the KP and EP for generic masonry structures. It is trivial to note that as for a Heyman model the EP and KP are dual (Iannuzzo et al., 2020), the numerical solution of one problem can be directly obtained through the dual solution of the dual LP problem through Lagrangian multipliers. In this sense, it is sufficient to numerically solve only one of those two LP problems. It is currently implemented for $2.5 \mathrm{D}$ geometries since the analysis is planar but non-uniform, symmetrical orthogonal depths can be considered. Displacements and mechanisms can be found simultaneously as the solution of two dual linear programming (LP) problems. Different mechanical problems can be tackled: stability in the initial configuration (Iannuzzo et al., 2020), effects of foundation displacements (Iannuzzo, 2019), assessment of the safety under horizontal actions (Iannuzzo et al., 2018, 2019), and, the effects of large foundation displacements (Iannuzzo et al., 2021b). In this paper, looking at a structure approximating a masonry bridge, we propose different studies using the PRD approach. The first analysis regards the stability of the initial, perfect configuration, and a numerical approach to evaluate the geometric safety factor (GSF) is provided. The second study looks at the effects of large foundation displacements affecting one of the piers. Four different scenarios, depending on the direction of the foundation displacement, are tackled, and the corresponding level of stability is evaluated performing a displacement capacity analysis. The third study proposes the load-bearing capacity analysis assuming a cracked configuration as the analysis's starting point. Different loading conditions, together with different profiles of foundation settlements, will be considered. We will show how the foundation displacement's value drastically affects the bridge's load-bearing capacity, also in term of collapse load multiplier. The last study looks at the effects of horizontal actions, and the bridge's stability will be measure through the evaluation of the horizontal static multiplier.

\section{PRD method}

This section shortly recalls the mathematical formulation of the PRD method, and how it allows coupling the search for a crack pattern/mechanism solving the KP with the corresponding internal stress state solving the EP.

\subsection{Constitutive relations: NRNT material and singular strain and stress fields}

With the PRD method, a 2D masonry structure is modelled as a continuum composed of NRNT material. The NRNT material frames the Heyman material model into continuum mechanics through three constitutive relations:

$$
\mathbf{T} \in \mathrm{Sym}^{-}, \mathbf{E} \in \mathrm{Sym}^{+}, \mathbf{T} \cdot \mathbf{E}=0
$$

in which $\mathbf{T}$ and $\mathbf{E}$ are the stress and latent strain tensors and where $\mathrm{Sym}^{-}$and $\mathrm{Sym}^{+}$are the mutual polar cones of semidefinite negative and positive symmetric tensors. Relations (1) are the necessary ingredients for applying limit analysis to masonry structures. For 
more info, the reader is referred to Angelillo (2014). For NRNT materials, both the strain $\mathbf{E}$ and stress $\mathbf{T}$ are bounded measures (Angelillo et al., 2014) and they can be decomposed additively into the sum of a regular part $(\cdot)^{\mathrm{r}}$ and a singular part $(\cdot)^{\mathrm{s}}$, that is:

$$
\mathbf{E}=\mathbf{E}^{\mathrm{r}}+\mathbf{E}^{\mathrm{s}}, \mathbf{T}=\mathbf{T}^{\mathrm{r}}+\mathbf{T}^{\mathrm{s}} .
$$

Both the singular part of the strain and stress tensor can be represented by Dirac delta distributions having 1D curves as supports. Furthermore, while the singular part of the strain can be used to model fractures, that is, displacement jumps occurring on lines (e.g., hinges), the singular part of the stress tensor can be adopted to model 1D compressive forces along lines (e.g., thrust lines). Even if a numerical method accounting for the regular part of the latent strain is possible (Iannuzzo et al., 2019), the PRD approach considers the only displacement jumps as admissible.

\subsection{Two energy criteria for NRNT materials}

For the NRNT material, two minimum energy criteria can be proved (Angelillo et al., 2018). The first reads: a solution of the BVP is represented by the displacement field $\mathbf{u}^{*}$ minimising the total potential energy $\wp(\mathbf{u})$ of the external loads in the space $\mathcal{K}$ of the admissible displacement fields $\mathbf{u}$, namely:

$$
\wp\left(\mathbf{u}^{*}\right)=\min _{\mathbf{u} \in \mathcal{K}} \wp(\mathbf{u}) .
$$

In this case, since we look for a solution of the BVP in the space of admissible displacement fields, we are solving the KP using a displacement approach.

The second dual criterion reads: a solution of the BVP is represented by the stress field $\mathbf{T}^{*}$ minimising the complementary energy $\wp_{c}(\mathbf{T})$ in the space $\mathcal{H}$ of the admissible stress fields $\mathbf{T}$, namely:

$$
\wp_{c}\left(\mathbf{T}^{*}\right)=\min _{\mathrm{u} \in \mathcal{H}} \wp(\mathbf{T}) .
$$

Conversely, in this case, we are solving the EP with an equilibrium approach, which also gives a rigorous mathematical framework to the approach adopted in the past centuries by many scientists. Indeed, every time we are looking for a thrust line of purely compressive forces lying within the structural geometry (this technically means that the stress state $\mathbf{T}$ is admissible), we are solving the BVP through an equilibrium approach.

\subsubsection{Primal LP problem}

The PRD method couples the two dual-energy criteria and frames them as two dual LP problems. In particular, once the structural domain is discretised into $\mathrm{M}$ elements

$$
\left(\Omega_{\mathrm{i}}\right)_{\mathrm{i} \in\{1, \ldots, \mathrm{M}\}},
$$

and the set of admissible displacement is assumed composed of piecewise-rigid displacements defined over (5), the minimum problem (3) can be written as the following LP problem:

$$
\text { minimise }-\mathbf{c} \cdot \mathbf{U}
$$


subject to

$$
\begin{aligned}
& \mathbf{A}_{\mathrm{ut}}^{\mathrm{int}} \mathbf{U} \geq 0, \mathbf{A}_{\mathrm{eq}}^{\mathrm{int}} \mathbf{U}=0 \\
& \mathbf{A}_{\mathrm{ub}}^{\mathrm{ext}} \mathbf{U} \geq \overline{\boldsymbol{\delta}}_{\mathrm{n}}, \mathbf{A}_{\mathrm{eq}}^{\mathrm{ext}} \mathbf{U}=-\overline{\boldsymbol{\delta}}_{\mathrm{t}},
\end{aligned}
$$

where

- $\quad \mathbf{U} \in \mathbb{R}^{3 \mathrm{M}}$ is the vector collecting the $3 \mathrm{M}$ rigid-body Lagrangian parameters (i.e., two translations and one rotation around, e.g., the centre of gravity) of the elements of equation (5)

- the vector $\mathbf{c} \in \mathbb{R}^{3 \mathrm{M}}$ collects the forces dual to the Lagrangian parameters $\mathbf{U}$

- $\quad \mathbf{A}_{\mathrm{ub}}^{\mathrm{int}}$ and $\mathbf{A}_{\mathrm{eq}}^{\mathrm{int}}$ are two matrices enforcing the Heyman's material restrictions (unilateral contact without sliding) on internal interfaces between two adjacent elements

- $\quad$ vectors $\overline{\boldsymbol{\delta}}_{\mathrm{n}}$ and $\overline{\boldsymbol{\delta}}_{\mathrm{t}}$ represent the normal and tangential component of prescribed boundary displacements, respectively

- $\quad \mathbf{A}_{\mathrm{ub}}^{\mathrm{ext}}$ and $\mathbf{A}_{\mathrm{eq}}^{\mathrm{ext}}$ are matrices used to enforce non-homogeneous boundary displacements ruled by the vectors $\overline{\boldsymbol{\delta}}_{\mathrm{n}}$ and $\overline{\boldsymbol{\delta}}_{\mathrm{t}}$.

Therefore, the objective function of the LP problem (6.1) is the discretised form of the total potential energy, whilst the constraints are represented by linear relations enforcing both Heyman's material restrictions (6.2) and prescribed boundary displacements (6.3).

\subsubsection{Dual LP problem}

The original problem $(\mathrm{P})$ gives rise to the following dual LP problem:

$$
\text { minimise }-\overline{\mathbf{f}}_{\mathrm{n}} \cdot \overline{\boldsymbol{\delta}}_{\mathrm{n}}-\overline{\mathbf{f}}_{\mathrm{t}} \cdot \overline{\boldsymbol{\delta}}_{\mathrm{t}}
$$

subject to

$$
\begin{aligned}
& \mathbf{A}_{\mathrm{ub}}^{\mathrm{T}} \mathbf{f}_{\mathrm{n}}+\mathbf{A}_{\mathrm{eq}}^{\mathrm{T}} \mathbf{f}_{\mathrm{t}}=\mathbf{c} \\
& \mathbf{f}_{\mathrm{n}} \leq 0, \mathbf{f}_{\mathrm{t}} \in \mathbb{R}^{2\left(\ell_{\mathrm{i}}+\ell_{\mathrm{c}}\right)}
\end{aligned}
$$

in which:

- the vectors $\overline{\mathbf{f}}_{\mathrm{n}}$ and $\overline{\mathbf{f}}_{\mathrm{t}}$ represent the emerging singular stress on the constrained boundary

- the matrix $\mathbf{A}_{\mathrm{ub}}^{\mathrm{T}}\left[\mathbf{A}_{\mathrm{eq}}^{\mathrm{T}}\right]$ is the transpose of the matrix $\mathbf{A}_{\mathrm{ub}}\left[\mathbf{A}_{\mathrm{eq}}\right]$ that collects vertically $\mathbf{A}_{\mathrm{ub}}^{\mathrm{int}}\left[\mathbf{A}_{\mathrm{ub}}^{\mathrm{ext}}\right]$ and $\mathbf{A}_{\mathrm{ub}}^{\mathrm{ext}}\left[\mathbf{A}_{\mathrm{eq}}^{\mathrm{ext}}\right]$

- $\quad$ the vectors $\mathbf{f}_{\mathrm{n}}$ and $\mathbf{f}_{\mathrm{t}}$ represent the emerging singular stress field on the boundary (internal and external) defined by the elements of equation (5). In particular, they are the forces dual of the unilateral (normal) and bilateral (tangential) kinematic constraints. 
Thus, this dual LP problem represents the discretised form of the minimum problem (4). Specifically, the objective function (7.1) is the discretised form of the complementary energy since it is the opposite of the work done by the reaction forces and the constrained displacements of the primal problem. The matrix expression (7.2) represents the equilibrium of the elements of equation (5) and it is ruled by the transpose of the kinematic matrices of the problem (6). Finally, inequalities (7.3) allow only for compressive forces.

It is worth to point out that, when there is a gap between two adjacent blocks (i.e., the relative displacement is non-zero), the corresponding force has to be zero since there is no contact. Conversely, if the forces on the boundary of the elements are non-zero, the relative dual displacement has to be zero. The solution of the dual problem (7) allows finding internal (between blocks) and external forces (on the constrained boundary) in an assembly of rigid block acting unilaterally without sliding. The first proof and an application of the minimum of the complementary energy for NRNT materials can be traced back in Angelillo et al. (2018).

Finally, the PRD method translates the minimum problems (3) and (4) into two dual LP problems (6) and (7), allowing fast computational solving since numerical algorithms such as the interior-point can be used. Moreover, we want to point out that the primal problem's solution directly provides (through the Lagrangian multipliers) the solution of the corresponding dual problem.

\subsubsection{Large displacement fields}

The way used to take into account large displacement fields is to recursively apply the PRD method on the deformed configuration in a step-by-step procedure. This procedure allows, at the same time, to keep fixed the NRNT material restrictions and to frame the displacement capacity analysis into a sequence of LP problems, that is, into a superimposition process of PRD analyses on the deformed and updated geometry. For this reason, large displacement fields are approximated through small PRDs in a superimposition process. This numerical procedure allows taking into account the effects of large foundation settlements on the stability of masonry structures, which are able to withstand even large foundation settlement (DeJong, 2016; McInerney and DeJong, 2015). In particular, the primal LP problem (6) after each step needs to be updated. It preserves the same form, and the dual problem (7) is always the dual of the updated problem (6). If we are performing a PRD displacement capacity analysis, this procedure takes place until the total potential energy (6.1) is not bounded from below anymore: the structure becomes unstable and collapses. For a detailed description, the reader is referred to Iannuzzo et al. (2021b).

\section{Numerical application: a masonry bridge}

In this section, looking at an approximate cross-section of a masonry bridge [Figure 1(a)], we show how compas_prd can address different mechanical scenarios, outlining the main peculiarities of its current implementation. Based on the PRD method, compas_prd is a Python-based computational tool, which currently can handle any $2.5 \mathrm{D}$ geometry; that is, the analysis is planar but non-uniform, symmetrical orthogonal depths can be considered. In Figure 1(a), the geometry and the discretisation of the structure composed of three 
identical shallow arches supported on four piers are depicted. For more details on the modelling of masonry arch bridges, the reader is referred to Proske and Van Gelder (2009) and Sarhosis et al. (2016), while in Gobbin et al. (2020) and an accurate modelling of the effect of the backfill in historic masonry vaults is provided.

The arches, having an internal radius of $2.00 \mathrm{~m}$, a thickness of $0.30 \mathrm{~m}$, a springing angle of $150^{\circ}$, are discretised into 21 voussoirs. The two external abutments have a height of $3.00 \mathrm{~m}$ and a width of $1.50 \mathrm{~m}$, while the internal ones have the same height but a width of $1.00 \mathrm{~m}$. All piers are partitioned with 16 blocks. The model's orthogonal depth is $1.00 \mathrm{~m}$, and four additional blocks [highlighted in blue in Figure 1(a)] are added as supports. As a load, we consider the self-weight for a uniform distribution of mass density $\left(\rho=1,800 \mathrm{~kg} / \mathrm{m}^{3}\right)$. Different mechanical problems are addressed: stability of the initial configuration (Subsection 3.1), effects of large foundation displacements (Subsection 3.2), effects of incremental loads in a deformed configuration (Subsection 3.3), and effects of horizontal loads (Subsection 3.3). Each PRD analysis is conducted solving the corresponding LP problem with CVXPY (Diamond and Boyd, 2016) and using the open-source solver ECOS (Domahidi et al., 2013). The computational time required to initialise the model, define and solve a single optimisation problem is about $0.05 \mathrm{~s}$ with an Intel ${ }^{\circledR}$ Core $^{\mathrm{TM}} \mathrm{i} 7-8850 \mathrm{H}$.

Figure 1 (a) Geometry and discretisation of an approximate cross-section of a masonry bridge

(b) Solution of the primal (6) and dual (7) problems for the initial perfect configuration (c)-(d) GSF assessment for the external, right abutment: two admissible stress states obtained by constraining the flow of forces to cross a tighter base obtained by symmetrically reducing the initial base through a scale factor $r$ - the GSF is obtained as the inverse of $r$ (see online version for colours)
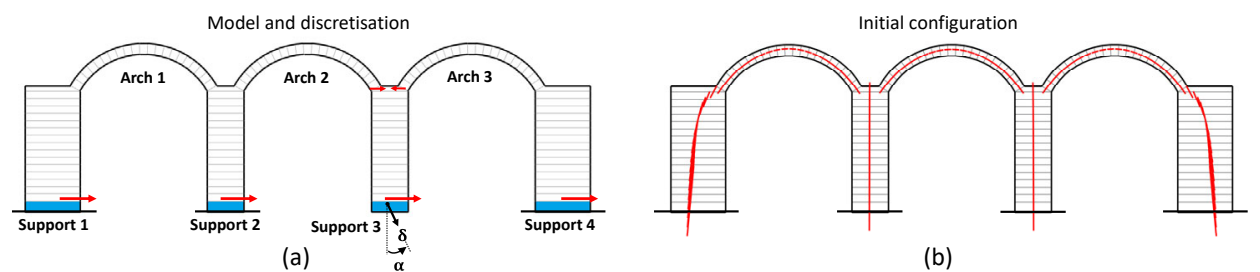

(b)

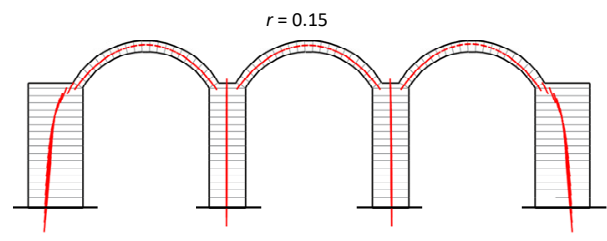

(c)

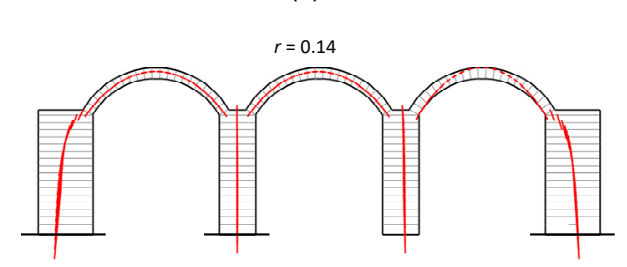

(d)

\subsection{PRD stability analysis of the initial configuration and GSF}

This section illustrates a PRD stability analysis of the structure in its initial, perfect configuration. The assessment of the stability level is pursed through a numerical approach proposed in Iannuzzo et al. (2020), which allows defining the GSF - the reader is referred to Heyman (1997) for its definition, and Cennamo et al. (2018a) and Cennamo and Cusano (2018) for standard applications. 
First, a PRD stability analysis of the structure is performed assuming zero boundary displacements (i.e., the supports are considered fixed). The solution of the primal problem (6) shows that the structure is stable as $\mathbf{U}=0$ is the minimiser of the total potential energy. The objective function of the corresponding dual problem (7) is zero and since the set of admissible stress states defined by constraints (7.2) and (7.3) is not void, infinite admissible stress solutions are possible [for more info the reader is referred to Iannuzzo et al. (2020)]. Figure 1(b) show one of the infinite admissible stress states. Note that the internal stress state is represented by reducing the interface forces to their resultants. It is worth to point out that this internal stress state is composed of compressive forces and is everywhere lying within the structural geometry.

The solution reported in Figure 1(b) shows that, because of both geometry and loads' symmetry, the flow of forces along the two internal piers is vertical and is acting on the centres of gravity of the two bases (supports 2 and 3). Therefore, the GSF of these two piers, for a gravity load condition, is infinite. Conversely, from Figure 1(b), it can easily be noted that the GSF of the two external abutments is not infinite. Therefore, an approach to evaluate the GSF of the outer, right pier consists in tightening the base forcing the flow of forces to go through a reduced interface until an admissible internal stress state can be still found [for more info the reader is referred to Iannuzzo et al. (2020)]. In Figures 1(c)-1(d), two admissible stress states obtained by reducing the actual base symmetrically with a scale factor $r$ are depicted. Specifically, the condition depicted in Figure 1(d) and corresponding to $r=0.14$ represents the ultimate limit state for which a compressive stress state lying within the structure can be still found. The corresponding GSF is 7.14. The total computational time needed to initialise, define and solve both the primal (6) and dual (7) problems is about 0.06 s with an Intel ${ }^{\circledR}$ Core $^{\mathrm{TM}} \mathrm{i} 7-8850 \mathrm{H}$.

\subsection{PRD displacement capacity analysis}

This section illustrates how the PRD method allows assessing the stability of the masonry bridge subjected to large foundation displacements. In particular, we test its stability referring to four different foundation profiles affecting the third pier. In recent years, the study of the foundation displacement effects represents a growing research interest (Acikgoz et al., 2017; Portioli and Cascini, 2017; D'Altri et al., 2019; Sangirardi et al., 2019; Spada, 2019; Pepe et al., 2020; Tiberti et al., 2020). Performing a displacement capacity analysis gives direct information about the closeness to the collapse of a structure showing a non-negligible crack pattern. Indeed, suppose we know the foundation profile causing the existing crack pattern. By increasing its magnitude, we can measure the structure's stability as the ratio among the maximum allowable displacement and the current one. Of course, the hypothesis at the base of the proposed approach is that the foundation profile's evolution can be described as a function of a scalar parameter.

The stability is assessed by performing a displacement capacity analysis and evaluating the maximum allowable displacement for which the structure is still stable. Notably, we assume that the third support is subjected to an increasing foundation displacement $\delta$ whose direction is defined by the angle $\alpha$ [Figure 1(a)]. Four values of $\alpha$ are considered: $0^{\circ}, 15^{\circ}, 30^{\circ}$ and $45^{\circ}$. Note that opposite values of $\alpha$ (i.e., $-0^{\circ},-15^{\circ},-30^{\circ}$ and $-45^{\circ}$ ) are not considered. Indeed, as it will be more evident in what follows, the present bridge's stability depends on the arches' geometry rather than on the piers' geometry. Indeed, the opposite values of $\alpha$ give rise to anti-symmetric results in terms of mechanisms and identical results in terms of maximum allowable displacements. Each 
analysis is conducted increasing the displacement $\delta$ in steps of $1 \mathrm{~cm}$ each until the structure collapses.

Figure 2 PRD displacement capacity analysis assuming a vertical $\left(\alpha=0^{\circ}\right)$, increasing foundation displacement $\delta$ affecting the third pier (see online version for colours)

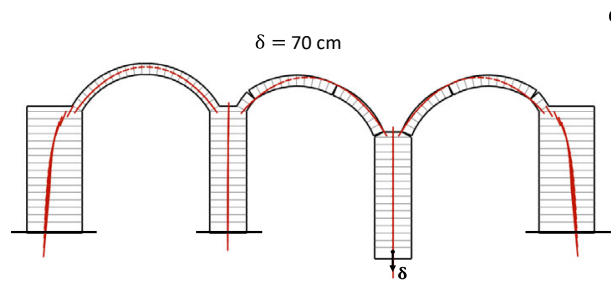

(a)

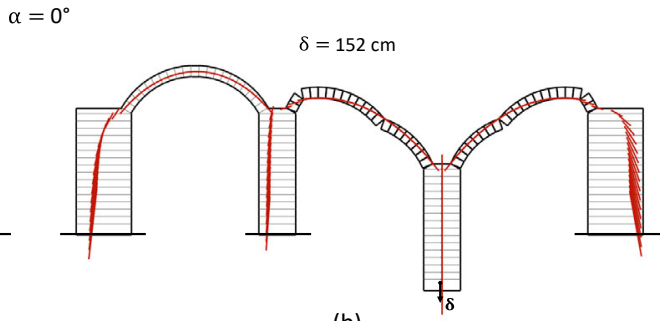

(b)

Notes: Configurations, crack patterns (bold, black lines) and resultant forces (red lines) for $\delta=70 \mathrm{~cm}$ (a) and for the unstable configuration due to $\delta=152 \mathrm{~cm}(\mathrm{~b})$.

Figure 2 shows the results of a PRD displacement capacity analysis assuming a vertical foundation displacement $\left(\alpha=0^{\circ}\right)$. The constraint (6.2) of the primal problem (6) are used to enforce the non-homogeneous, incremental, boundary displacement. The solution of the primal problem (6) is the displacement vector $\mathbf{U}$ collecting the Lagrangian parameters of the blocks. Since $\mathbf{U} \neq 0$, displacement jumps among adjacent blocks occur. The set of all displacement jumps represents the structure's crack pattern needed to accommodate the foundation displacement.

The displacement capacity analysis is performed solving a sequence of LP problems on the updated geometry. As soon as a small settlement $(\delta=1 \mathrm{~cm})$ occurs, both the arches supported by the third pier show a three-hinge mechanism [Figure 2(a)]. This mechanism remains qualitatively the same until $\delta$ reaches the value of $151 \mathrm{~cm}$ representing the maximum allowable displacement. Indeed, for $\delta=152 \mathrm{~cm}$ [Figure 2(b)], the structure starts collapsing: because of the symmetry, the collapse involves both the arches while the piers are still in a stable condition. The total computational time needed for the entire displacement capacity analysis (about 200 steps) is about $8 \mathrm{~s}$ with an Intel ${ }^{\circledR}$ Core $^{\mathrm{TM}}$ i7-8850H.

Figure 3 shows the results of PRD displacement capacity analysis assuming a settlement whose direction is defined by $\alpha=15^{\circ}$ [Figure 1(a)]. As in the previous case, the LP problems are solved in a superimposition process allowing for the evolution of the mechanism/crack pattern during the motion. Indeed, to accommodate the increasing foundation displacement, the structure shows ten, different, qualitative mechanisms (Figure 3) until $\delta$ reaches the value of $113 \mathrm{~cm}$ when the arch 2 becomes unstable. In this case, the total computational time required is about $9 \mathrm{~s}$ with an Intel ${ }^{\circledR}$ Core $^{\mathrm{TM}} \mathrm{i7}-8850 \mathrm{H}$.

Two further PRD displacement capacity analyses are performed assuming a foundation displacement whose direction is defined by $\alpha$ equals $30^{\circ}$ (Figure 4 ) and $45^{\circ}$ (Figure 5). The capacity in term of displacements is $85 \mathrm{~cm}$ and $65 \mathrm{~cm}$, respectively. In both cases, the structure collapses when the arch 2 reaches an unstable configuration [Figures 4(d) and 5(b)]. For $\alpha=30^{\circ}$, the bridge shows four different qualitative mechanisms during the motion. Conversely, the initial crack pattern remains the same until the collapse state when $\alpha=45^{\circ}$. The computational time required for these two PRD displacement capacity analyses is about $7 \mathrm{~s}$ and $5 \mathrm{~s}$ with an Intel® Core $^{\mathrm{TM}} \mathrm{i7}-8850 \mathrm{H}$. 
Figure 3 PRD displacement capacity analysis for a foundation displacement $\delta$ affecting the third pier and whose direction [Figure 1(a)] is defined by $\alpha=15^{\circ}$ (see online version for colours)

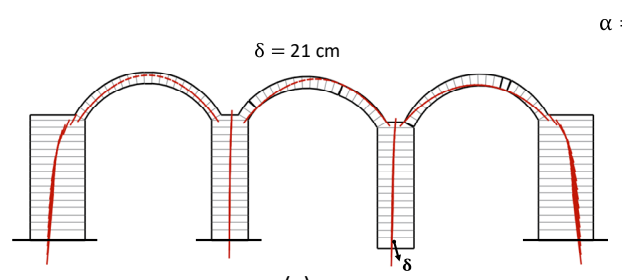

(a)

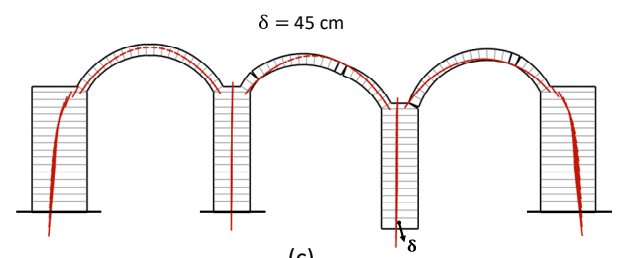

(c)

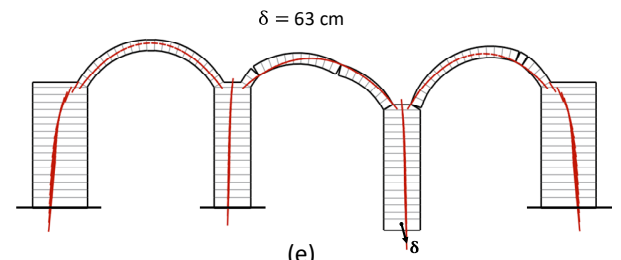

(e)

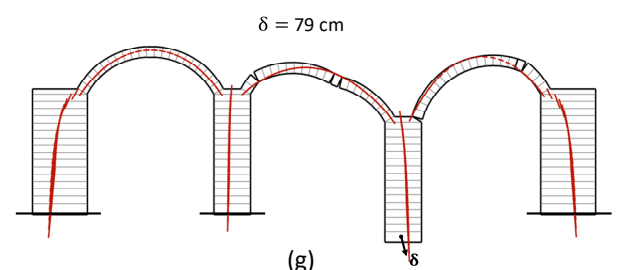

(g)

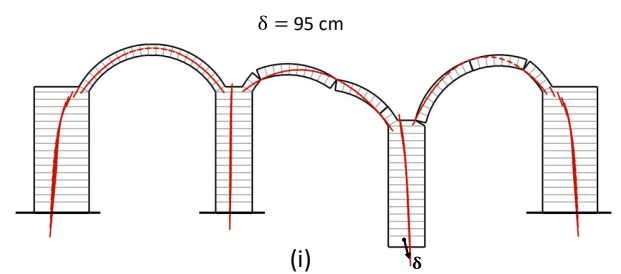
$\alpha=15^{\circ}$

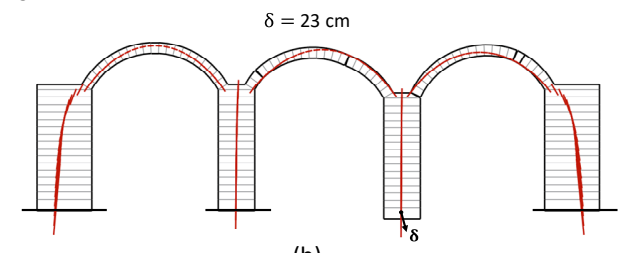

(b)

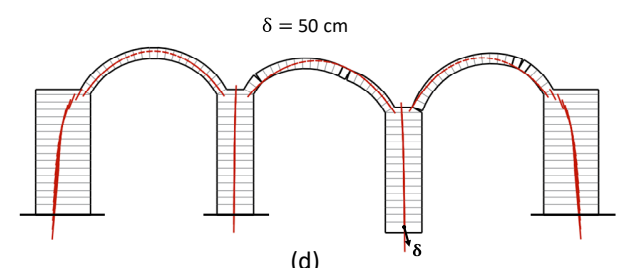

(d)

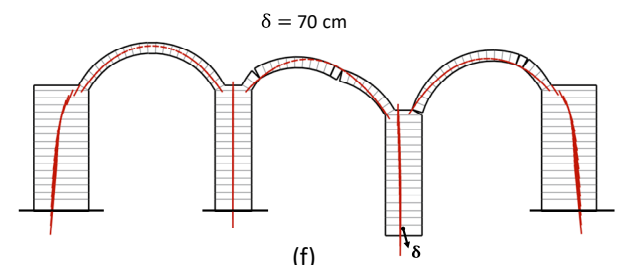

(f)

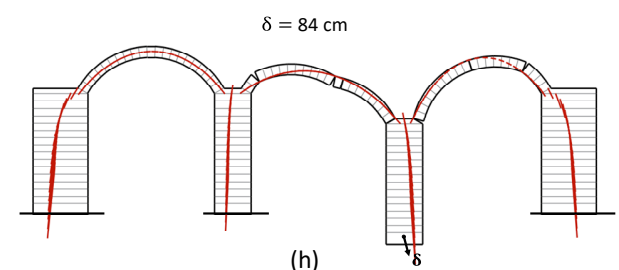

(h)

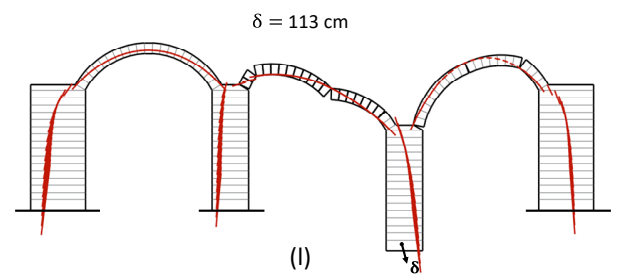

Note: Ten qualitative, different mechanisms are used by the bridge to accommodate the increasing foundation displacement $\delta$ until the structural collapse (1).

In all the cases, as the reader can see, the crack pattern solving the primal problem (6) and the corresponding internal stress state, solving the dual problem (7), are perfectly compatible: when a new hinge (crack) forms the thrust goes through the centre of rotation, and if a hinge, during the motion, closes up, the corresponding resultant forces can get back to act over the internal interface. 
Figure 4 PRD displacement capacity analysis assuming a foundation displacement $\delta$ defined by $\alpha=30^{\circ}$ [Figure 1(a)] (see online version for colours)

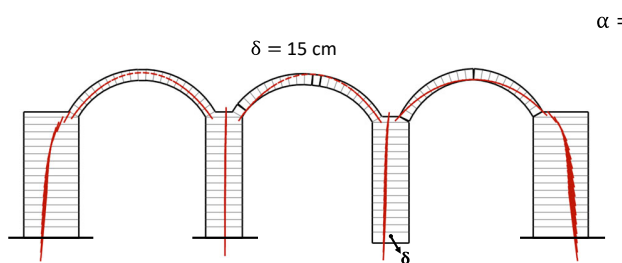

(a)

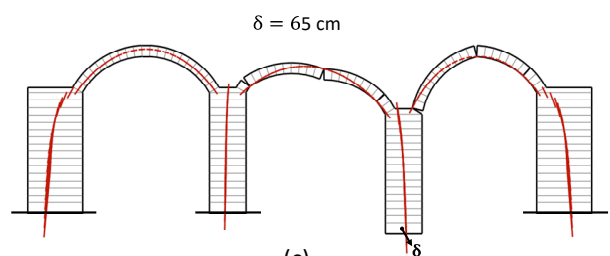

(c) $\alpha=30^{\circ}$

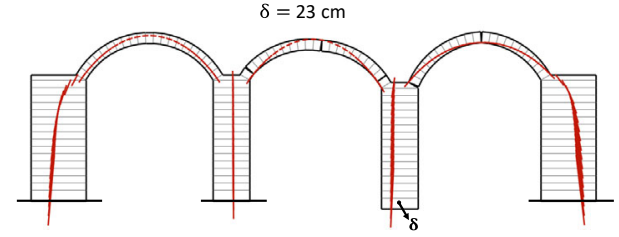

(b)

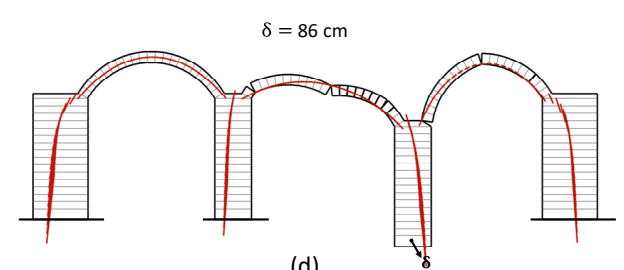

(d)

Notes: Representation of the main mechanisms and corresponding internal until the collapse (d).

Figure 5 PRD displacement capacity analysis assuming a foundation displacement $\delta$ defined by $\alpha=45^{\circ}$ [Figure 1(a)] (see online version for colours)

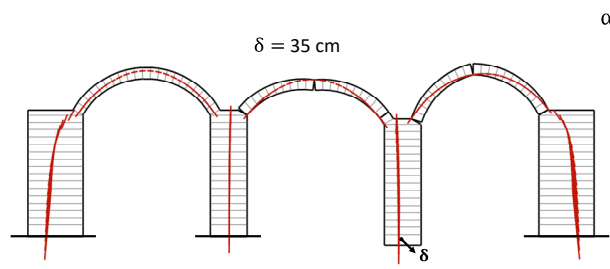

(a)

$\alpha=45^{\circ}$

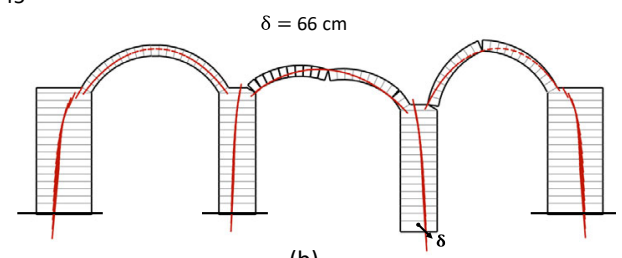

(b)

Notes: The initial $(\delta=1 \mathrm{~cm})$ mechanism remains qualitative the same, e.g., $\delta=35 \mathrm{~cm}$ (a), until the structure collapses $\delta=66 \mathrm{~cm}(\mathrm{~b})$. Crack pattern and corresponding internal forces are compatible.

\subsection{PRD load-bearing capacity analysis}

This section illustrates the PRD method's potentials in performing load-bearing capacity analyses with non-homogeneous boundary conditions. To this aim, we propose a complex mechanical scenario. We want to define the load-bearing capacity of the masonry bridge assuming as reference configuration the one depicted in Figure 6, where the structure shows a crack pattern due to a $10 \mathrm{~cm}$ third pier's settlement whose direction is defined by $\alpha=15^{\circ}$. Two different, vertical, asymmetric loading conditions affecting the second arch are considered (Figure 6). In both cases, the variable load's magnitude is increased in steps of $0.05 \mathrm{kN} / \mathrm{m}$ each, until the structure collapses. This procedure gives rise to a sequence of LP problems. The maximum value of the load that the structure can stably withstand corresponds to the last value for which the total potential energy is still bounded from below. When the total potential energy is not bounded from below 
anymore, it is impossible to find an equilibrated configuration, and the structure turns into a collapse mechanism.

Figure 6 PRD load-bearing capacity analysis of the bridge subjected to non-homogeneous boundary conditions (see online version for colours)

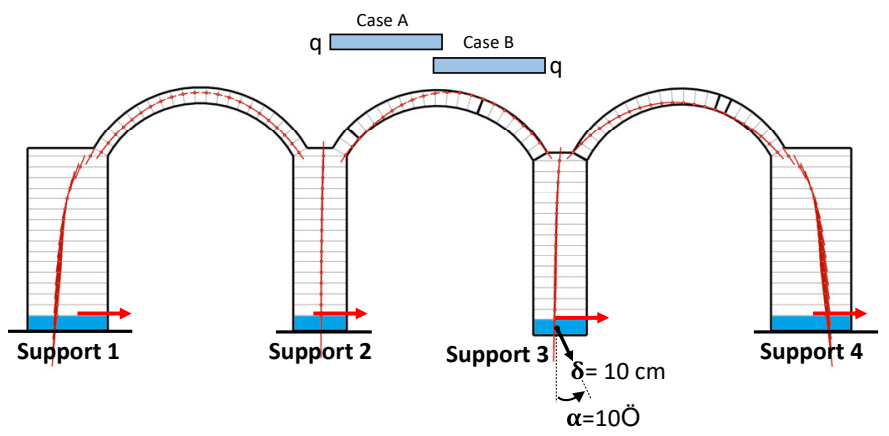

Notes: The third pier has settled $\left(\delta=10 \mathrm{~cm}, \alpha=15^{\circ}\right)$. The bridge's deformed configuration is assumed as a reference configuration for the load-bearing capacity analysis considering two different loading cases (cases A and B, respectively).

The initial crack pattern (corresponding to the foundation settlement's reference value of $10 \mathrm{~cm}$ ) defines a rigid macro-block partition of the structural domain as depicted in Figure 6. However, additional, increasing loads force the structure to reach a new equilibrium configuration: old hinges (cracks) close and new hinges open up. In this sense, the rigid macroblock partition evolves to accommodate increasing loads in new stable, cracked configurations. Figures 6 and 8 report the evolution of the mechanisms in the two different loading cases of Figure 6, i.e., cases A and B, respectively. Moreover, Figures 6(e) and 8(e) show the last stable configurations, while Figures 6(f) and 8(f) the collapse mechanisms. It is worth noting that the maximum load capacity in case $A$ is $25.60 \mathrm{kN} / \mathrm{m}$ while in cases $B$ is $26.55 \mathrm{kN} / \mathrm{m}$. The difference is due to the initial crack pattern, which determines a non-symmetric crack pattern. The total computational time needed for the entire load-bearing capacity analysis (considering small incremental steps of $0.05 \mathrm{kN} / \mathrm{m}$ each, which gives rise to a sequence of about $600 \mathrm{LP}$ problems!), including the initialisation of the model and the starting displacement capacity analysis needed to define the cracked configuration, is about $25 \mathrm{~s}$ with an Intel ${ }^{\circledR}$ Core $^{\mathrm{TM}} \mathrm{i7}-8850 \mathrm{H}$.

\subsection{PRD seismic capacity analysis}

In this section, we assess the level of stability of the bridge subjected to horizontal actions. The usual way to account for seismic actions is to simulate them with horizontal forces proportional to the self-weight using a scale factor $\lambda$. Once $\lambda$ reaches a specific value, the structure becomes a mechanism (Fortunato et al., 2014; Iannuzzo et al., 2018, 2020). From this point onwards the mechanics is dominated by the rocking (DeJong and Ochsendorf, 2010; DeJong and Dimitrakopoulos, 2014; Mauro et al., 2015; Dimitrakopoulos and DeJong, 2012; Como et al., 2019; Meriggi et al., 2019) where the role of the friction becomes relevant (Monaco et al., 2014). The rocking behaviour of masonry structures can be clearly seen in experimental tests (Krstevska et al., 2020) and 
it represents a further, but ultimate, resource to resist severe actions (Como, 2019) even if it leads to chaotic behaviour (Mascolo, 2019).

Figure 7 PRD load-bearing capacity analysis with non-homogeneous boundary conditions: case A (Figure 6), (a) (b) (c) (d) (e) evolution of mechanisms and internal stress states used by the bridge to accommodate increasing loads (f) collapse mechanisms (see online version for colours)

Case A

$\alpha=15^{\circ}, \delta=10 \mathrm{~cm}$

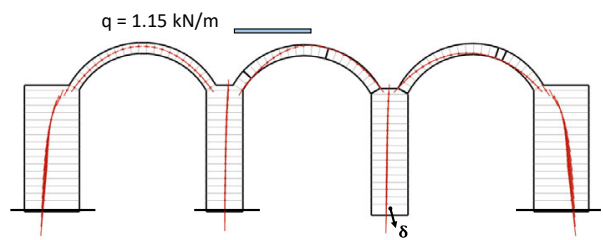

(a)



(c)

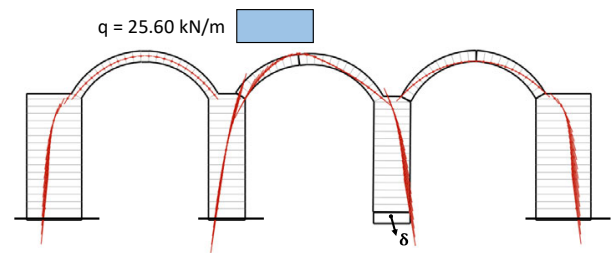

(e)

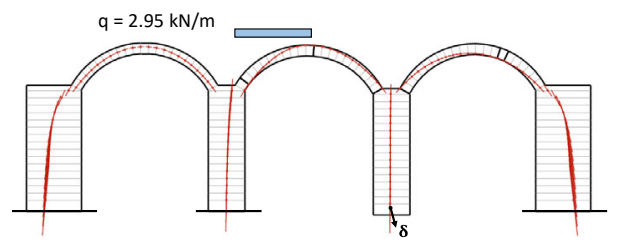

(b)



(d)

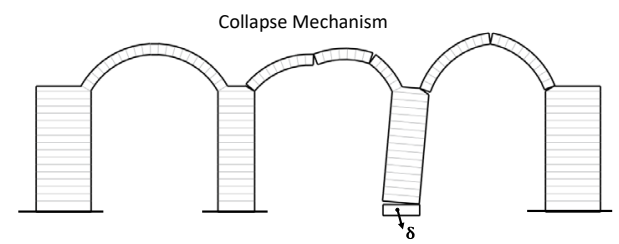

(f)

In Figure 9, solutions of both the primal (6) and dual (7) problems for increasing values of $\lambda$ are reported. For low values [Figures 9(a)-9(b)], the structure is stable but the flow of forces to be in equilibrium with the increasing horizontal loads gets more inclined with respect to a vertical axis. When $\lambda$ reaches the value of 0.30 [Figure 9(c)], the structure becomes a mechanism [Figure 9(d)]. Arches 1 and 3 become a three-hinge mechanism, while arch 2 shows only two hinges. Three further cracks open up at the base of the piers 2,3 , and 4. The corresponding resultant forces are perfectly compatible with the mechanism: when a hinge forms the resultant force goes through the centre of rotation. It has to be underlined how the hinges' position in the arches moves from the left to the right part of the structure (Figure 9). 
Figure 8 PRD load-bearing capacity analysis with non-homogeneous boundary conditions: case B [Figure 1(a)], (a) (b) (c) (d) (e) evolution of stable mechanisms and internal stress states used by the masonry bridge to accommodate increasing loads (f) collapse mechanisms (see online version for colours)

Case B

$\alpha=15^{\circ}, \delta=10 \mathrm{~cm}$

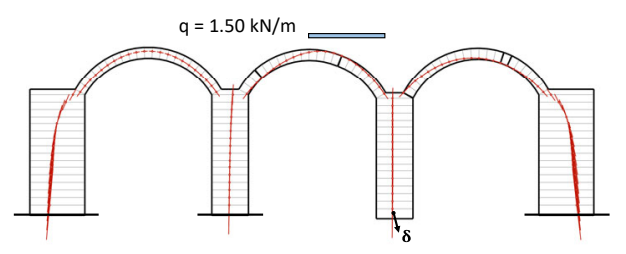

(a)

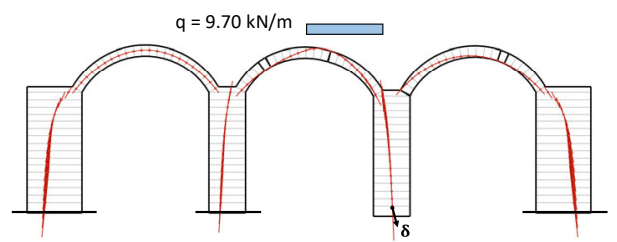

(c)

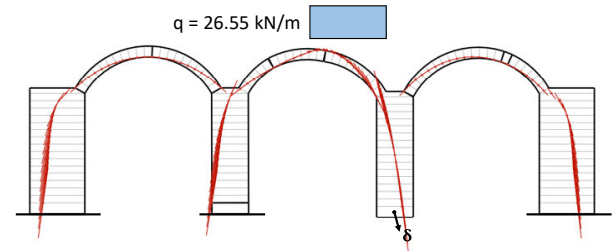

(e)

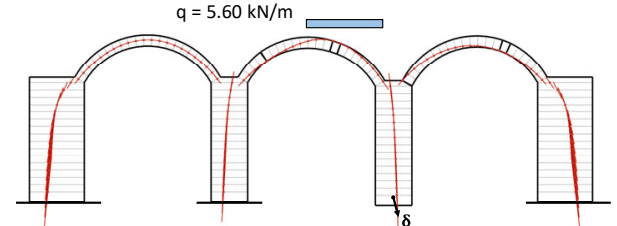

(b)

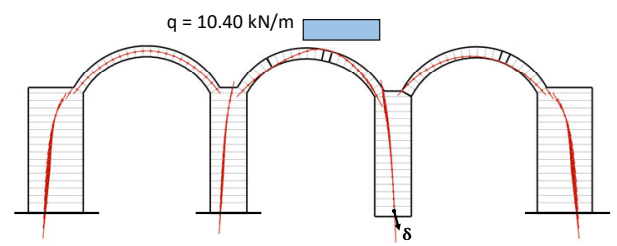

(d)

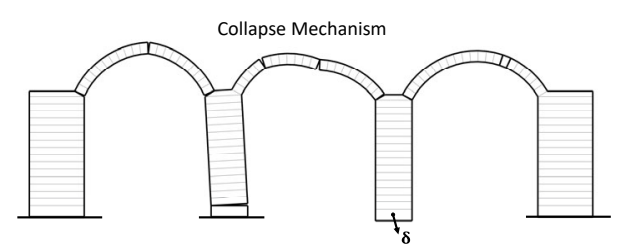

(f)

Figure 9 PRD horizontal capacity analysis of the structure for increasing values of the horizontal static multiplier $\lambda$ (see online version for colours)

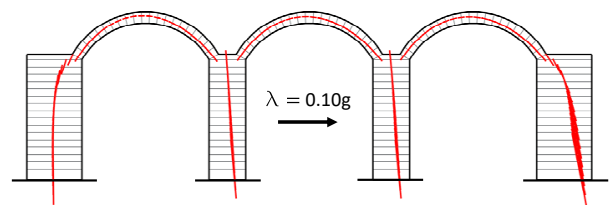

(a)

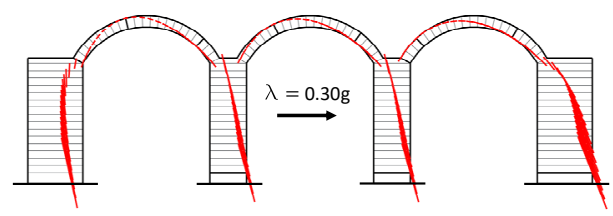

(c)

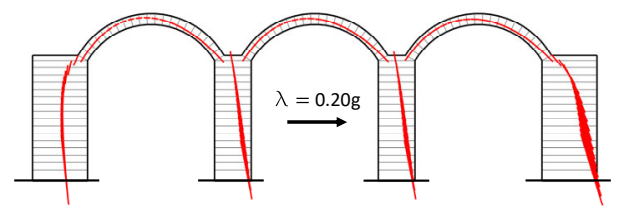

(b)

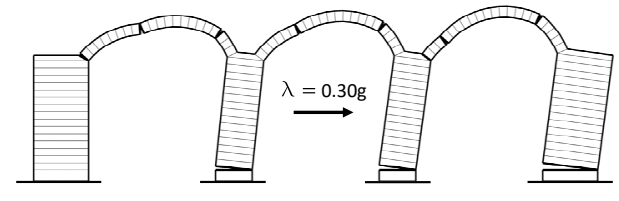

(d)

Notes: For low values of $\lambda$, the structure is stable $(a, b)$. For $\lambda=0.30$, the structure becomes a mechanism (d) whose internal stress state is depicted in (c). 


\section{Discussion}

In this section, we discuss the main features of the PRD analyses referring to Section 3. Subsection 3.1 showed that the masonry bridge in its initial, perfect configuration is stable and, also, infinite admissible internal stress states are possible. We assessed the stability level through the evaluation of the GSF. Moreover, it is worth noting that the GSF evaluation's numerical procedure also represents a way to select one of the infinite, admissible stress solutions. This feature perfectly fits the limit analysis spirit: in the undeformed configuration, infinite admissible, stress states are possible, and trying to find the actual stress state (the 'true' line of thrust) in a perfect configuration is hopeless.

Figure 10 PRD displacement capacity analyses, (a) in horizontal thrust (dimensionless to the total weight of the structure) exerted on support 3 and 4 (b) in horizontal thrust (dimensionless to the arch's weight) exerted by arch 2 and 3 on pier 3 (see online version for colours)

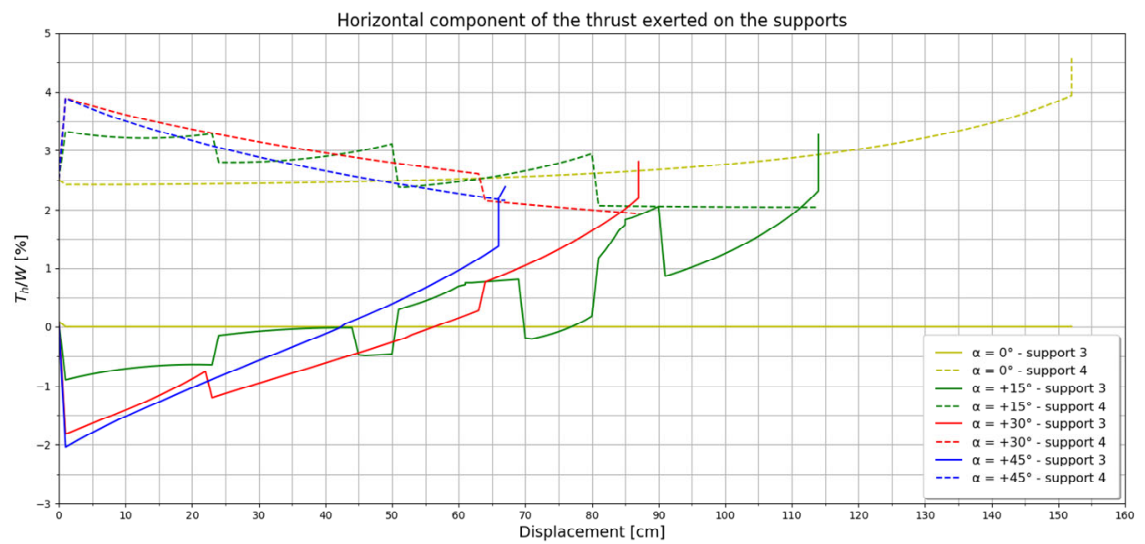

(a)

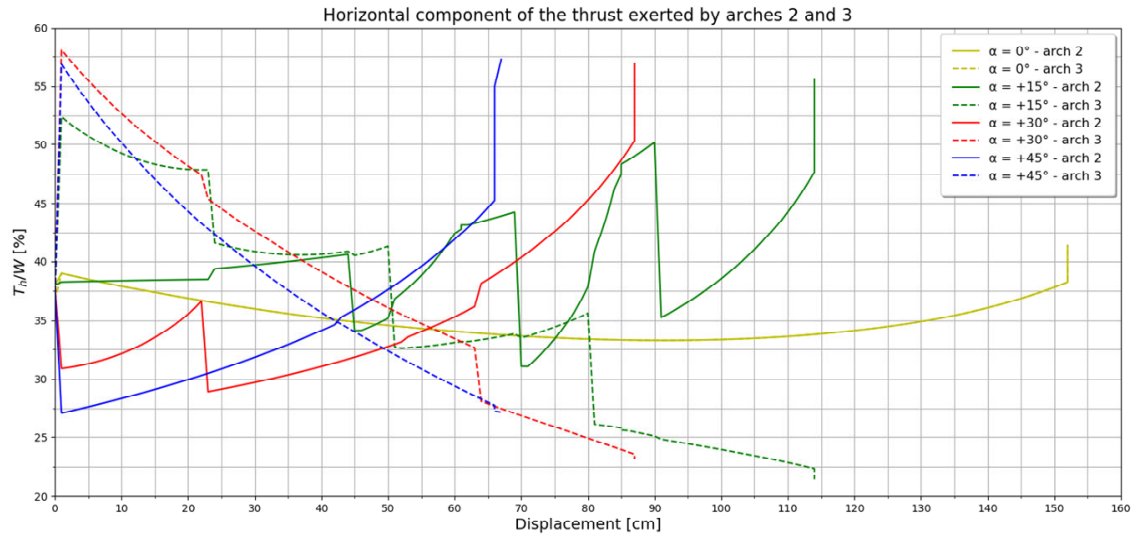

(b)

Notes: For $\alpha=0^{\circ}$, the horizontal thrusts exerted by the arch 2 and 3 on the third pier are equal because of the symmetric mechanism. Consequently, the horizontal thrust on support 3 is everywhere zero [Figure 10(a)]. 
Subsection 3.2 assessed the bridge's stability for increasing foundation settlements performing some PRD displacement capacity analyses. First, these analyses clearly illustrated the peculiar behaviour of masonry structures which accommodate foundation displacements through a rigid macro-block partition of the structural domain. Moreover, increasing foundation displacements are accommodated through an evolution of the mechanism/crack pattern (Figures 2-6) until a part of the (or the whole) structure becomes unstable. This aspect highlights how the intrinsic weakness of masonry structures represented by their unilaterality turns into a ductile response for small foundation settlements, making them resilient to small external environment changes.

Referring to the displacement capacity analyses, in Figure 10(a), we report the diagram of the horizontal thrust exerted on the supports 3 and 4. At the same time, Figure 10(b) shows the horizontal thrust exerted on the third pier by the second and third arch. Both diagrams show several jumps. These jumps occur whether the mechanism switches from one configuration to another or if the internal stress state suddenly changes (Iannuzzo et al., 2021b). Moreover, all the curves show an initial jump for $\delta=1 \mathrm{~cm}$ : as soon as the structure undergoes a small settlement, it decomposes into rigid macro-blocks and accommodates this slight change in the boundary conditions in a new, deformed configuration. Consequently, the horizontal thrust (of the moving part of the structure) suddenly changes (e.g., in the presented cases, it drops down). While the blue and yellow curves do not show other jumps, the red and green ones show other jumps due to the changes in the mechanisms highlighted in Figures 3 and 4. Moreover, looking at Figure 10(b), it has to be noted that curves having a vertical asymptote at the collapse identify the collapsing part of the structure: except for $\alpha=0^{\circ}$ (where both arch 2 and 3 are collapsing, i.e., the mechanism is symmetric), in the remaining cases, the collapse involves only the second arch.

Subsection 3.3 looked at assessing the bridge's load-bearing capacity, not in its undeformed configuration, but assuming a cracked structure as the starting point for our analysis. The bridge in a cracked configuration $\left(\delta=10 \mathrm{~cm}, \alpha=15^{\circ}\right.$, Figure 6$)$ was loaded until its collapse referring to two different asymmetric, loading conditions. The main aim of the analysis was to illustrate how the PRD approach provides a consistent energy-based approach to face complex problems where the evolution of the mechanism (closing of old cracks and opening of new fractures) is key.

Figure 11 shows the trend of the horizontal and vertical thrusts exerted on the supports as a function of the variable loads both in cases $A$ and $B$, respectively. Also, in the present case, jumps on the thrusts identify changes in the mechanism as noted before. Moreover, looking at the thrusts diagrams, intervals showing a simultaneous, non-smooth trend suggest that part of the bridge connecting the corresponding supports is statically undetermined. Specifically, the meaning is that the thrust line can be slightly translated and the related internal stress state is still admissible. Indeed, looking at the load-bearing capacity of Figure 8, the left part of the bridge connecting supports 1,2 and 3 is statically undetermined up to $5.60 \mathrm{kN} / \mathrm{m}$. For variable loads greater than $5.60 \mathrm{kN} / \mathrm{N}$ only the structural part connecting supports 1 and 2 remains statically undetermined. The nonsmooth trend of the curves (red, yellow and green) of Figure 11(b) clearly illustrates this behaviour.

Finally, to show how the foundation settlement's initial value can significantly affect the load-bearing capacity of the bridge, in Figure 12 we report the collapse load multiplier (with respect to a given live load of $1 \mathrm{kN} / \mathrm{m}$ ) as a function of the foundation displacement and for the two different loading cases of Figure 6. Additionally, the 
collapse multiplier is evaluated, referring to all four foundation settlement profiles analysed in Subsection 3.2.

Figure 11 PRD load-bearing capacity analyses, (a) and (b) horizontal (c) and (d) vertical thrusts (dimensionless to the total weight of the structure) exerted on supports and corresponding to the two asymmetric loading conditions of Figure 6 (cases A and B, respectively) (see online version for colours)

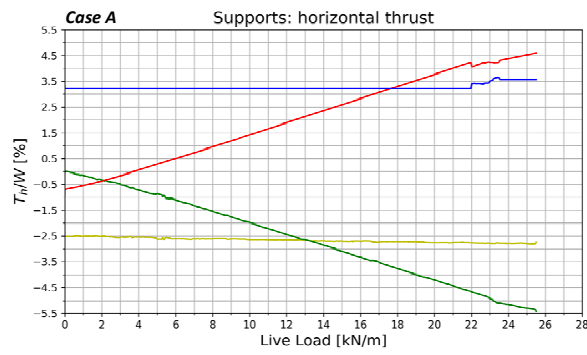

(a)

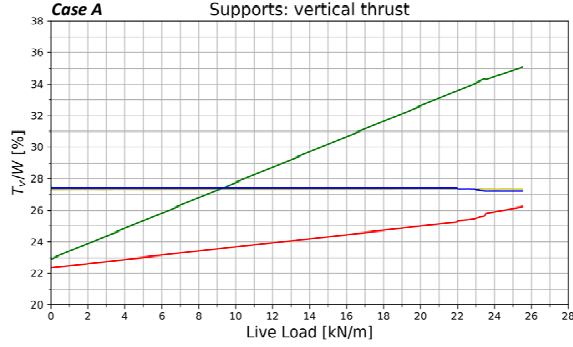

(c)

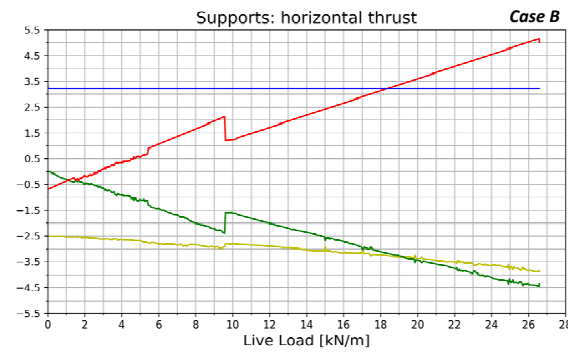

(b) $\begin{array}{rr} & \\ \text { Support } 2 & \text { - Supporl } 3 \\ \text { Support } 4\end{array}$



(d)

Figure 12 PRD load-bearing capacity analyses with non-homogeneous boundary conditions: collapse multiplier (reference load equals to $1 \mathrm{kN} / \mathrm{m}$ ) as a function of the foundation displacement, (a) and (b) the two loading conditions of Figure 6 (cases A and B) are considered (see online version for colours)

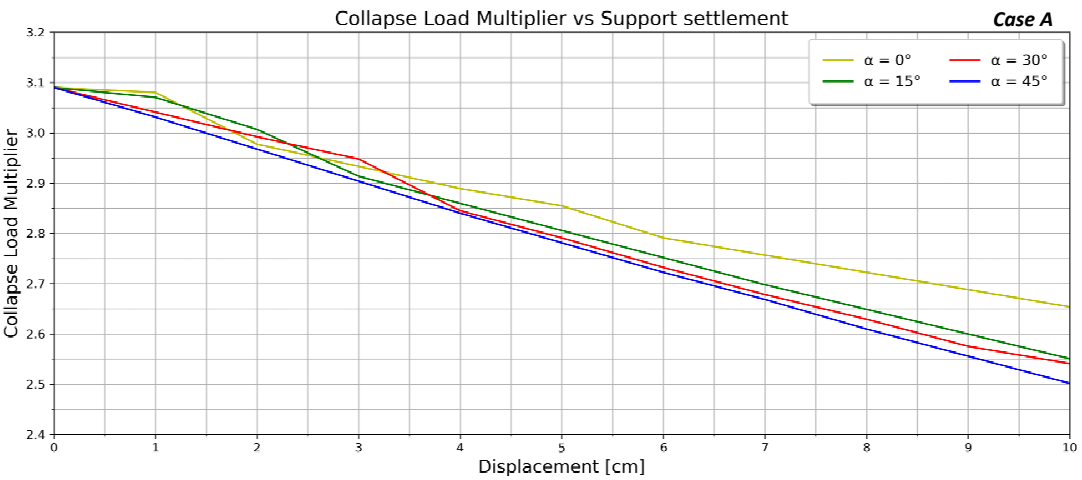

(a)

Notes: Moreover, the analysis is performed referring to the four foundation profiles studied in Subsection 3.2. As the reader can note, the collapse multiplier rapidly decreases with increasing foundation displacements. 
Figure 12 PRD load-bearing capacity analyses with non-homogeneous boundary conditions: collapse multiplier (reference load equals to $1 \mathrm{kN} / \mathrm{m}$ ) as a function of the foundation displacement, (a) and (b) the two loading conditions of Figure 6 (cases A and B) are considered (continued) (see online version for colours)

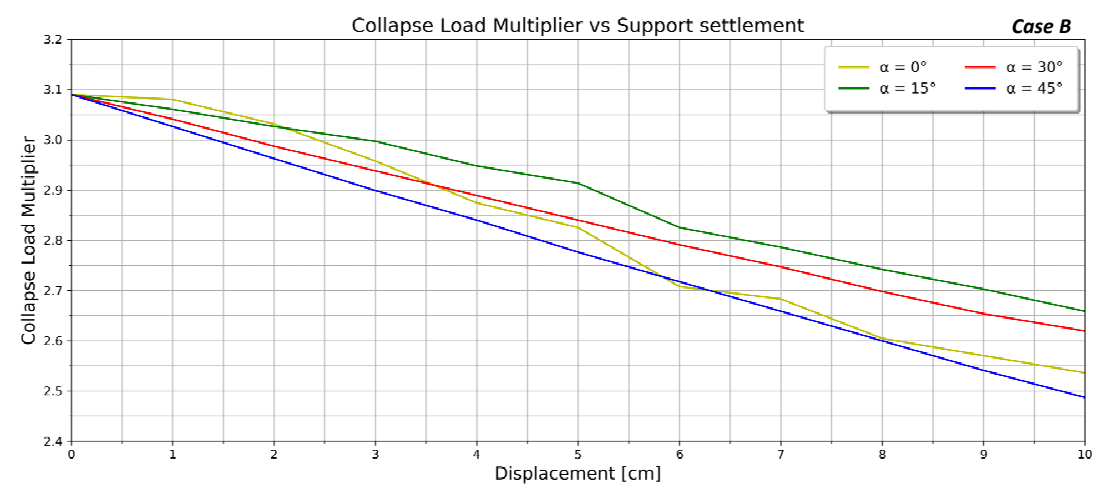

(b)

Notes: Moreover, the analysis is performed referring to the four foundation profiles studied in Subsection 3.2. As the reader can note, the collapse multiplier rapidly decreases with increasing foundation displacements.

Specifically, we replicate the study performed in Subsection 3.3 for each profile of Subsection 3.2, and for different values of the foundation settlement (up to $10 \mathrm{~cm}$, a reasonable value of the foundation displacement). As the reader can note, for a foundation settlement of $10 \mathrm{~cm}$, the green curves restitute the collapse load found in Subsection 3.3. Moreover, looking at the diagrams of Figure 12, it is worth noting how the collapse multiplier rapidly decreases with increasing foundation settlements. It goes from about 3.1 for a perfect, non-cracked configuration, to 2.5-2.7 when the initial configuration it the one associated to a $10 \mathrm{~cm}$ yielding of the third pier. Subsection 3.4 showed how the PRD method provides a straightforward approach to assess the horizontal static multiplier and identify the structure's crack pattern when it starts rocking. Finally, we want to point out that the current implementation of the PRD method provides a fast computational solving of various mechanical problems as it can solve a sequence of hundreds of LP problems in a few seconds as shown for both the displacement and load-bearing capacity analyses.

\section{Conclusions}

This paper has presented peculiarities and abilities of compas_prd, a new, Python-based tool framed within COMPAS masonry (Iannuzzo et al., 2021a). It is based on the PRD method (Iannuzzo, 2017), representing a fast, computational, limit analysis, displacement-based approach for assessing masonry structures.

The PRD approach's key aspect relies on using displacements as primal variables, which allows handling BVP with mixed boundary conditions, i.e., taking into account non-homogeneous boundary-displacements and forces at the same time. It is based on two dual-energy criteria (i.e., minimum of the total potential and complementary energy), and, thus, it allows coupling mechanisms and corresponding internal stress states even in 
the presence of large foundation displacements. Moreover, it allows to perform and assess masonry structures without making any assumptions on the mechanism's shape or considering only a fixed number of mechanisms in advance.

In particular, looking at an approximate cross-section of a multi-span masonry bridge, we have demonstrated how compas_prd in a few seconds provides mechanisms and corresponding internal forces for different mechanical problems: stability of the reference configuration, effects of large displacements, load-bearing capacity analyses on a cracked configuration, and effects of horizontal actions. Furthermore, for each problem, a measure of the closeness to the collapse have been provided through GFS, maximum allowable displacement, collapse load and horizontal static multiplier.

The first key point of all the proposed analyses is that the PRD approach provides a fast, energy-based and robust limit analysis strategy to solve both classical mechanical problems and non-standard problems in which non-homogeneous boundary conditions play a crucial role. Additionally, another key aspect is that it not only provides information about limit states (e.g., collapse loads or the maximum allowable displacements); but it also provides information about fractures and internal stress states for structures that, subjected to external loads and settlements, are still in a stable configuration.

\section{Acknowledgements}

This work was supported by the Swiss National Science Foundation (SNSF) - Project Grant No. 178953: 'Practical stability assessment strategies for vaulted unreinforced masonry structures'.

\section{References}

Acikgoz, S., Soga, K. and Woodhams, J. (2017) 'Evaluation of the response of a vaulted masonry structure to differential settlements using point cloud data and limit analyses', Construction and Building Materials, September, Vol. 150, pp.916-931, doi.org/10.1016/j.conbuildmat. 2017.05.075.

Aita, D., Barsotti, R. and Bennati, S. (2019) 'Equilibrium analysis of a sail vault in Livorno's Fortezza Vecchia through a modern re-edition of the stability area method', in Conference of the Italian Association of Theoretical and Applied Mechanics, Springer, Cham, pp.989-998.

Angelillo, M. (2014) 'Practical applications of unilateral models to masonry equilibrium', in Angelillo, M. (Ed.): Mechanics of Masonry Structures, pp.109-210, Springer, Vienna.

Angelillo, M. et al. (2018) 'Rigid block models for masonry structures', International Journal of Masonry Research and Innovation, Vol. 3, No. 4, pp.349-368.

Angelillo, M., Fortunato, A., Montanino, A. and Lippiello, M. (2014) 'Singular stress fields in masonry structures: Derand was right', Meccanica, Vol. 49, No. 5, pp.1243-1262.

Angelillo, M., Olivieri, C., DeJong, M.J. (2021) 'A new equilibrium solution for masonry spiral stairs’, Engineering Structures, Vol. 238, doi.org/10.1016/j.engstruct.2021.112176.

Barsi, F., Barsotti, R. and Bennati, S. (2019) 'Equilibrium of masonry sail vaults: the case study of a subterranean vault by Antonio da Sangallo the Elder in the 'Fortezza Vecchia', in Livorno', in Conference of the Italian Association of Theoretical and Applied Mechanics, Springer, Cham, pp.2094-2103.

Block, P. (2009) Thrust Network Analysis: Exploring Three-Dimensional Equilibrium, Doctoral dissertation, Massachusetts Institute of Technology. 
Block, P. and Lachauer, L. (2014a) 'Three-dimensional (3D) equilibrium analysis of gothic masonry vaults', International Journal of Architectural Heritage, Vol. 8, No. 3, pp.312-335.

Block, P. and Lachauer, L. (2014b) 'Three-dimensional funicular analysis of masonry vaults', Mechanics Research Communications, March, Vol. 56, pp.53-60, https://doi.org/10.1016/ j.mechrescom.2013.11.010.

Block, P. and Ochsendorf, J.A. (2007) 'Thrust network analysis: a new methodology for three-dimensional equilibrium', Journal of the International Association for Shell and Spatial Structure, Vol. 48, No. 3, pp.167-173.

Block, P., Ciblac, T. and Ochsendorf, J.A. (2006) 'Real-time limit analysis of vaulted masonry buildings', Computers \& structures, Vol. 84, Nos. 29-30, pp.1841-1852.

Brandonisio, G., Angelillo, M. and De Luca, A. (2020) 'Seismic capacity of buttressed masonry arches’, Engineering Structures, July, Vol. 215, doi.org/10.1016/j.engstruct.2020.110661.

Bruggi, M. (2020) 'A constrained force density method for the funicular analysis and design of arches, domes and vaults', International Journal of Solids and Structures, June, Vol. 193, pp.251-269, doi.org/10.1016/j.ijsolstr.2020.02.030.

Cennamo, C. and Cusano, C. (2018) 'The gothic arcade of Santa Maria Incoronata in Naples. Equilibrium of gothic arches', Int. J. Mason. Res. Innov., Vol. 3, No. 2, pp.92-107.

Cennamo, C., Cusano, C. and Angelillo, M. (2018a) 'On the statics of large domes: a static and kinematic approach for San Francesco di Paola in Naples', in Milani, G., Taliercio, A. and Garrity, S. (Eds.): Proceedings of the 10th International Masonry Conference.

Cennamo, C., Cusano, C., Angelillo, M. and Fortunato, A. (2018b) 'A study on form and seismic vulnerability of the Dome of San Francesco di Paola in Naples', Ing. Sismica-Ital, Vol. 35, pp.88-108.

Como, M. (2013) Statics of Historic Masonry Constructions, Springer, Berlin.

Como, M. (2019) 'The rocking: a resource for the side strength of masonry structures', Journal of Mechanics of Materials and Structures, Vol. 14, No. 5, pp.751-770.

Como, M., Di Carlo, F. and Coccia, S. (2019) 'Dynamic response of rocking cracked masonry walls', Meccanica, Vol. 54, No. 3, pp.381-398.

D'Altri, A.M. et al. (2019) 'Historic barrel vaults undergoing differential settlements', International Journal of Architectural Heritage, pp.1-14, doi.org/10.1080/15583058.2019. 1596332.

De Chiara, E. et al. (2019) 'Automatic generation of statically admissible stress fields in masonry vaults', Journal of Mechanics of Materials and Structures, Vol. 14, No. 5, pp.719-737.

De Serio, F. et al. (2018) 'Masonry structures made of monolithic blocks with an application to spiral stairs', Meccanica, Vol. 53, No. 8, pp.2171-2191.

DeJong, M. J. (2016) 'Settlement effects on masonry structures', Structural Analysis of Historical Constructions: Anamnesis, diagnosis, therapy, controls-Proceedings of the 10th International Conference on Structural Analysis of Historical Constructions, SAHC 2016, January, pp.449-456.

DeJong, M.J. and Dimitrakopoulos, E.G. (2014) 'Dynamically equivalent rocking structures', Earthquake Engineering \& Structural Dynamics, Vol. 43, No. 10, pp.1543-1563.

DeJong, M.J. and Ochsendorf, J.A. (2010) 'Dynamics of in-plane arch rocking: an energy approach', Proceedings of the Institution of Civil Engineers-Engineering and Computational Mechanics, Vol. 163, No. 3, pp.179-186.

Diamond, S. and Boyd, S. (2016) 'CVXPY: a Python-embedded modeling language for convex optimization', The Journal of Machine Learning Research, Vol. 17, No. 1, pp.2909-2913.

Dimitrakopoulos, E.G. and DeJong, M.J. (2012) 'Revisiting the rocking block: closed-form solutions and similarity laws', Proceedings of the Royal Society A: Mathematical, Physical and Engineering Sciences, Vol. 468, No. 2144, pp.2294-2318. 
Domahidi, A., Chu, E. and Boyd, S. (2013) 'An SOCP solver for embedded systems', 2013 European Control Conference (ECC), pp.3071-3076, July, IEEE. DOI: 10.23919/ECC.2013. 6669541.

Fortunato, A., Fraternali, F. and Angelillo, M. (2014) 'Structural capacity of masonry walls under horizontal loads', Ingegneria Sismica, Vol. 31, No. 1, pp.41-49.

Fraddosio, A., Lepore, N. and Piccioni, M.D. (2020) 'Thrust surface method: an innovative approach for the three-dimensional lower bound limit analysis of masonry vaults', Engineering Structures, Vol. 202, p.109846, doi.org/10.1016/j.engstruct.2019.109846.

Fraternali, F. (2010) 'A thrust network approach to the equilibrium problem of unreinforced masonry vaults via polyhedral stress functions', Mechanics Research Communications, Vol. 37, No. 2, pp.198-204.

Fraternali, F., Angelillo, M. and Fortunato, A. (2002) 'A lumped stress method for plane elastic problems and the discrete-continuum approximation', International Journal of Solids and Structures, Vol. 39, No. 25, pp.6211-6240.

Fuentes, P. (2019) 'Mechanics of flying buttresses: the case of the cathedral of Mallorca', Journal of Mechanics of Materials and Structures, Vol. 13, No. 5, pp.617-630.

Gesualdo, A. et al. (2020) 'Minimum energy strategies for the in-plane behaviour of masonry', Frattura ed Integrità Strutturale, Vol. 14, No. 51, pp.376-385.

Gobbin, F., de Felice, G. and Lemos, J.V. (2020) 'A discrete element model for masonry vaults strengthened with externally bonded reinforcement', International Journal of Architectural Heritage, pp.1-14, doi.org/10.1080/15583058.2020.1743792.

Heyman, J. (1966) 'The stone skeleton', International Journal of Solids and Structures, Vol. 2, No. 2, pp.249-279.

Heyman, J. (1997) The Stone Skeleton: Structural Engineering of Masonry Architecture, Cambridge University Press, Cambridge.

Heyman, J. (2019) 'The structural engineer's view of ancient buildings', Journal of Mechanics of Materials and Structures, Vol. 13, No. 5, pp.609-615.

Huerta, S. (2006a) 'Geometry and equilibrium: the gothic theory of structural design', The Structural Engineer, Vol. 84, No. 2, pp.23-28.

Huerta, S. (2006b) 'Galileo was wrong: the geometrical design of masonry arches', Nexus Network Journal, Vol. 8, No. 2, pp.25-52.

Iannuzzo, A. (2017) A New Rigid Block Model for Masonry Structures, PhD dissertation, Università degli Studi di Napoli Federico II.

Iannuzzo, A. (2019) 'Energy based fracture identification in masonry structures: the case study of the church of 'Pietà dei Turchini', Journal of Mechanics of Materials and Structures, Vol. 14, No. 5, pp.683-702.

Iannuzzo, A. et al. (2018) 'Fractures detection in masonry constructions under horizontal seismic forces', Ingegneria Sismica, Vol. 35, No. 3, pp.87-103.

Iannuzzo, A. et al. (2021a) 'COMPAS masonry: a computational framework for practical assessment of unreinforced masonry structures', Proceedings of the SAHC Symposium, Barcelona.

Iannuzzo, A., Dell'Endice, A., Van Mele, T. and Block, P. (2021b) 'Numerical limit analysis-based modelling of masonry structures subjected to large displacements', Computers \& Structures, Vol. 242, p.106372, doi.org/10.1016/j.compstruc.2020.106372.

Iannuzzo, A., Van Mele, T. and Block, P. (2020) 'Piecewise rigid displacement (PRD) method: a limit analysis-based approach to detect mechanisms and internal forces through two dual energy criteria', Mechanics Research Communications, Vol. 107, p.103557 [online] http://doi. org/10.1016/j.mechrescom.2020.103557.

Iannuzzo, A., Olivieri, C. and Fortunato, A. (2019) 'Displacement capacity of masonry structures under horizontal actions via PRD method', Journal of Mechanics of Materials and Structures, Vol. 14, No. 5, pp.703-718. 
Krstevska, L., Nikolić, Ž. and Kustura, M. (2020) 'Shake table testing of two historical masonry structures for estimation of their seismic stability', International Journal of Architectural Heritage, Vol. 15, No 1, pp.45-63. doi.org/10.1080/15583058.2020.1779870.

Kurrer, K.E. (2018) The History of the Theory of Structures: Searching for Equilibrium, John Wiley \& Sons, Doi: 10.1002/9783433609163.

Marmo, F. and Rosati, L. (2017) 'Reformulation and extension of the thrust network analysis', Computers \& Structures, Vol. 182, pp.104-118, doi.org/10.1016/j.compstruc.2016.11.016.

Marmo, F., Masi, D. and Rosati, L. (2018) 'Thrust network analysis of masonry helical staircases', International Journal of Architectural Heritage, pp.1-21, doi.org/10.1080/15583058.2017. 1419313.

Mascolo, I. (2019) 'Recent developments in the dynamic stability of elastic structures', Frontiers in Applied Mathematics and Statistics, Vol. 5, No. 51, doi.org/10.3389/fams.2019.00051.

Mauro, A., de Felice, G. and DeJong, M.J. (2015) 'The relative dynamic resilience of masonry collapse mechanisms', Engineering Structures, Vol. 85, pp.182-194, doi.org/10.1016/ j.engstruct.2014.11.021.

McInerney, J. and DeJong, M.J. (2015) 'Discrete element modeling of groin vault displacement capacity', International Journal of Architectural Heritage, Vol. 9, No. 8, pp.1037-1049.

Meriggi, P. et al. (2019) 'Distinct element modelling of masonry walls under out-of-plane seismic loading', International Journal of Architectural Heritage, Vol. 13, No. 7, pp.1110-1123.

Monaco, M., Bergamasco, I. and Betti, M. (2019) 'A no-tension analysis for a brick masonry vault with lunette', Journal of Mechanics of Materials and Structures, Vol. 13, No. 5, pp.703-714.

Monaco, M., Guadagnuolo, M. and Gesualdo, A. (2014) 'The role of friction in the seismic risk mitigation of freestanding art objects', Natural Hazards, Vol. 73, No. 2, pp.389-402.

Ochsendorf, J.A. (2002) Collapse of Masonry Structures, Doctoral dissertation, University of Cambridge.

Olivieri, C. et al. (2021) 'Parametric design of purely compressed shells', Mechanics of Materials [online] http://doi.org/10.1016/j.mechmat.2021.103782.

Paris, V., Pizzigoni, A. and Adriaenssens, S. (2020) 'Statics of self-balancing masonry domes constructed with a cross-herringbone spiraling pattern', Engineering Structures, Vol. 215, p.110440, doi.org/10.1016/j.engstruct.2020.110440.

Pepe, M. et al. (2020) 'Discrete and continuous approaches for the failure analysis of masonry structures subjected to settlements', Frontiers in Built Environment, Vol. 6, No. 43, doi.org/10.3389/fbuil.2020.00043.

Portioli, F. and Cascini, L. (2017) 'Large displacement analysis of dry-jointed masonry structures subjected to settlements using rigid block modelling', Engineering Structures, Vol. 148, pp.485-496, https://doi.org/10.1016/j.engstruct.2017.06.073.

Proske, D. and Van Gelder, P. (2009) Safety of Historical Stone Arch Bridges, Springer Science \& Business Media, doi: 10.1007/978-3-540-77618-5.

Roca, P., López-Almansa, F., Miquel, J. and Hanganu, A. (2007) 'Limit analysis of reinforced masonry vaults', Engineering Structures, Vol. 29, No. 3, pp.431-439.

Rondeaux, J.F., Deschuyteneer, A. and Zastavni, D. (2018) 'Assessing geometrically the structural safety of masonry arches', in Wouters, I., Van de Voorde, S., Bertels, S., Espion, B., De Jonge, K. and Zastavni, D. (Eds.): Building Knowledge, Constructing Histories, Proceedings of 6th International Congress on Construction History (6ICCH), pp.1129-1136.

Sangirardi, M., Malena, M. and de Felice, G. (2019) 'Settlement induced crack pattern prediction through the jointed masonry model', in Conference of the Italian Association of Theoretical and Applied Mechanics, Springer, Cham, pp.1971-1980.

Sarhosis, V., De Santis, S. and de Felice, G. (2016) 'A review of experimental investigations and assessment methods for masonry arch bridges', Structure and Infrastructure Engineering, Vol. 12, No. 11, pp.1439-1464. 
Shin, H.V. et al. (2016) 'Reconciling elastic and equilibrium methods for static analysis', $A C M$ Transactions on Graphics, Vol. 35, No. 2, pp.1-16.

Spada, A. (2019) 'The effect of vertical ground movement on masonry walls simulated through an elastic-plastic interphase meso-model: a case study', Archive of Applied Mechanics, Vol. 89, No. 8, pp.1655-1676.

Tiberti, S., Grillanda, N., Mallardo, V. and Milani, G. (2020) 'A genetic algorithm adaptive homogeneous approach for evaluating settlement-induced cracks in masonry walls', Engineering Structures, Vol. 221, p.111073, doi.org/10.1016/j.engstruct.2020.111073.

Tralli, A., Chiozzi, A., Grillanda, N. and Milani, G. (2020) 'Masonry structures in the presence of foundation settlements and unilateral contact problems', International Journal of Solids and Structures, Vol. 191, pp.187-201, doi.org/10.1016/j.ijsolstr.2019.12.005. 